\title{
PENGARUH CITRA PENGELOLA KUBURAN DESA TERUNYAN TERHADAP MINAT KUNJUNGAN WISATAWAN
}

\author{
Ni Made Reni Istariani \\ I Made Sendra \\ I Putu Sudana \\ Email : reniistariani@gmail.com \\ PS. S1 Industri Perjalanan Wisata \\ Fakultas Pariwisata UNUD
}

\begin{abstract}
Bali is one famous island with many potential tourism. Bangli as one of the district in Bali has begun develop it's own potential tourism. There is a cultural village which has uniqueness called Terunyan Village Cemetery. The village cemetery has uniqueness due to the corpse is not buried or burned but placed under the tree after the death ceremony. The uniqueness this village has developed a tourist destination inducing tourist are interested in visiting Terunyan Cemetery. However the cadger and boat driver had made the tourist to be afraid to visit the Terunyan Cemetery which emerged the bad image. The research used the purposive sampling methode as a technique to determine the respondent. The number of respondents were 110 respondents. The technique of data analysis used multiple linear regression. Research in parsial show that the mirror image has a positive and significant effect toward the interesting of tourist visiting Terunyan Village Cemetery. Moreover, current image has positive and significant effect toward the tourist's interest. In addition, wish image has positive and significant influence toward the interesting to visit. Fouthermore, corporate image has positive and significant influence to the interesting of tourist to visit. By simultaneously image has positive and significant effect toward the interesting of tourist to visit Terunyan Cemetery.
\end{abstract}

Keywords: Image, Interest, Terunyan Village Cemetery.

\section{PENDAHULUAN}

Bali merupakan provinsi yang memiliki potensi pariwisata yang sangat besar. Bali merupakan daerah tujuan wisata yang terkenal di dunia, keindahan alam dan kebudayaan Bali yang unik dan beranekaragam menjadi daya tarik tersendiri bagi para wisatawan. Bali memiliki keunikan dan keunggulan kebudayaan, yaitu adanya perpaduan yang harmonis antara potensi kebudayaan yang masih memegang teguh adat istiadat dan sumber daya manusia dengan dukungan alam yang mempesona menjadi modal dasar dari keunggulan pariwisata daerah Bali. Salah satu kabupaten di Bali yang memiliki banyak potensi wisata dan keindahan panorama adalah Kabupaten Bangli. Salah satu kecamatan di Kabupaten Bangli yang memiliki banyak daya tarik wisata adalah Kecamatan Kintamani. Daya tarik wisata yang menarik untuk dikunjungi di Kecamatan Kintamani diantaranya Danau Batur dan Gunung Batur, di tepian Danau Batur terdapat sebuah desa kuno yaitu Desa Terunyan. Desa Terunyan merupakan Desa Bali Aga, atau sering disebut Desa Bali Mula. Terdapat tradisi unik yang dimiliki oleh masyarakat Desa Terunyan dalam segi penguburan jenazah, Desa Terunyan memiliki tradisi bahwa seseorang yang telah meninggal, jenazahnya tidak dikubur atau dibakar melainkan hanya diletakkan di bawah pohon setelah upacara kematian. Masyarakat Desa Terunyan sering menyebut pohon tersebut dengan nama pohon menyan. Meskipun Desa Terunyan memiliki keunikan pada tradisinya, namun tingkat 
kunjungan wisatawan yang berkunjung ke Desa Terunyan tersebut sedikit, hal itu terjadi dikarenakan kurang adanya promosi yang dilakukan oleh pihak pengelola Desa Terunyan. Selain hal tersebut adanya citra yang tidak baik dari Desa Terunyan membuat wisatawan takut untuk berkunjung ke desa tersebutr. Salah satu citra yang kurang baik di mata wisatawan terhadap Desa Terunyan adalah adanya pengemis yang memaksa untuk diberikan uang serta adanya pendayung yang nakal saat wisatawan menyebrang menuju kuburan Desa Terunyan yaitu meminta tarif penyebrangan yang lebih tinggi dibandingkan dengan tarif sebenarnya. Hal tersebut yang membuat wisatawan enggan untuk berkunjung ke kuburan Desa Terunyan. Namun saat ini telah terjadi penggantian pengurus yang menangani Desa Terunyan untuk membuat sebuah perbaikan di Desa Terunyan. Pengelola Desa Terunyan saat ini telah mulai memperbaiki peraturan desa agar tidak terjadi kejadian yang membuat citra Desa Terunyan menjadi buruk kembali. Peraturan yang saat ini ada pada Desa Terunyan sudah mampu memperbaiki citra dari Desa Terunyan di mata wisatawan yang mana hal tersebut diharapkan dapat meningkatkan minat wisatawan untuk berkunjung ke Desa Terunyan.

Kualitas potensi yang ada jika tidak dibarengi dengan sumber daya manusia yang berkualitas tentu saja perkembangan pariwisata tersebut tidak akan berjalan dengan baik. Menyadari arti penting industri pariwisata bagi perkembangan ekonomi masyarakat, maka setiap daya tarik wisata harus berusaha memberikan layanan terbaik kepada wisatawan. Tujuan dari kegiatan tersebut adalah untuk membangun citra yang kuat dalam rangka menghasilkan daya tarik yang kuat dari sebuah destinasi. Manfaat dari citra tersebut adalah untuk meningkatkan minat kunjungan wisatawan. Dengan adanya suatu citra yang baik serta potensi dari Kuburan Desa Terunyan tentu akan meningkatkan minat kunjungan wisatawan sehingga perkembangan pariwisata desa dapat meningkat. Membangun citra yang positif pada wisatawan tentu akan membantu meningkatkan perkembangan daya tarik wisata Desa Terunyan. Penting bagi pengelola Desa Terunyan untuk memperbaiki atau meningkatkan citra positif tentang Desa Terunyan sehingga membantu meningkatkan minat wisatawan berkunjung ke Kuburan Desa Terunyan.

Setiap destinasi tentu mengharapkan citra yang baik di mata wisatawan, hal tersebut tentu juga diharapkan oleh Desa Terunyan untuk meningkatkan minat wisatawan, hal tersebut yang membuat citra Desa Terunyan akan mempengaruhi minat kunjungan wisatawan. Citra destinasi akan memainkan peran penting, baik dalam menarik ataupun menahan wisatawan (Andreassen \& Lindestad, 1998).

Citra adalah serangkaian kepercayaan yang dihubungkan dengan sebuah gambaran yang dimiliki atau diperoleh dari pengalaman hal ini diungkapkan (Huddleston dalam Syarifuddin dan Suryanto 2016:156). Citra adalah kesan seseorang atau individu tentang sesuatu yang muncul sebagai hasil dari pengetahuan dan pengalamannya (Frank Jefkins dalam Syarifuddin dan Suryanto 2016:156). Citra yang positif merupakan salah satu nilai lebih yang dapat membuat wisatawan berminat untuk berkunjung kesebuah destinasi wisata. Jenis-jenis Citra menurut (Frank Jefkins dalam Syarifuddin dan Suryanto 2016:156) membagi citra dalam beberapa jenis, yaitu citra bayangan, citra yang berlaku, citra yang diharapkan, citra pengelola. Untuk itu ingin diketahui pengaruh citra pengelola kuburan Desa Trunyan terhadap minat kunjungan wisatawan.

\section{METODE PENELITIAN}

Terdapat empat indikator dari citra yaitu: mirror image (citra bayangan), current image (citra berlaku), wish image (citra yang diharapkan), corporate image (citra pengelola). Sedangkan pada variabel minat menggunakan minat yang diekspresikan (expresed interest), minat yang diwujudkan (manifested interst), minat yang diinventarisasikan (inventored interst).

Teknik pengumpulan data menggunakan teknik observasi, wawancara terstuktur, kuesioner, dan studi kepustakaan. Dalam penentuan responden yang akan mengisi kuesioner ditentukan secara porposive sampling, yaitu pengambilan anggota sampel secara sengaja, sesuai dengan persyaratan sampel yang ditentukan, bila yang bersangkutan dianggap mampu memberikan informasi yang berhubungan dengan penelitian (Sugiyono, 2010:300). Jumlah responden yang 
diambil adalah sebanyak 110 responden. Teknik analisis data yang digunakan adalah analisis regresi berganda.

\section{HASIL}

\section{Karakteristik Wisatawan}

Karakteristik wisatawan berdasarkan jenis kelamin yang mendominasi adalah lakilaki sebanyak $69 \%$ dengan usia yang mendominasi adalah rentan usia dari 21-30 tahun dengan jenis pekerjaan yang mendominasi adalah pegawai swasta. Negara asal yang mendominasi adalah dari Indonesia dengan jumlah kunjungan ke kuburan Desa Terunyan yang mendominasi adalah sebanyak 1 kali dengan tingkat pendidikan terakhir adalah diploma/S1/S2/S3 dengan media informasi yang didapat untuk mengetahui Desa Terunyan adalah melalui sosial media.

\section{Hasil Analisis Data}

Validitas disetiap pernyataan pada penelitian ini menunjukan valid, hal tersebut ditunjukan dengan adanya nilai $r_{\text {hitung }}$ yang lebih tinggi dari $r_{\text {tabel }}$ yang ditentukan yaitu sebesar 0,187 (Ghozali, 2005). Sedangkan untuk uji reabilitas menunjukan bahwa nilai Alpha Cronbach's menunjukan nilai yang lebih besar dari nilai reabilitas yaitu sebesar 0,6 .

Uji Asumsi Klasik memiliki tiga uji yaitu Hasil uji normalitas menunjukan nilai $0,508>0,05$, hal ini menunjukan bahwa data berdistribusi secara normal. Sedangkan Hasil uji multikolinearitas menunjukan nilai Tolerance semua variabel lebih besar dari 0,1 dan nilai VIF lebih kecil dari 10 yaitu untuk citra bayangan sebesar 0,608 dan nilai VIF 1.645 , citra yang berlaku sebesar 0,473 dan nilai VIF 2.116, citra yang diharapkan sebesar 0,506 dan nilai VIF 1.977 dan citra pengelola sebesar 0,703 dan nilai VIF 1,422. Hal tersebut membuktikan bahwa tidak terjadi multikolinearitas. Untuk hasil uji heteroskedatisitas menunjukan bahwa nilai nilai signifikasi semua variabel bernilai lebih besar dari 0,05 yaitu citra bayangan sebesar 0,630 , citra yang berlaku sebesar 0,964 , citra yang diharapkan sebesar 0,611 , dan citra pengelola sebesar 0,752 .

Hasil analisis korelasi menunjukan bahwa adanya hubungan pada setiap variabel yang mana hubungan pada citra bayangan menunjukan hubungan yang cukup kuat terhadap minat kunjungan yaitu 0,678. Pada citra yang berlaku menunjukan hubungan yang cukup kuat terhadap minat kunjungan yaitu sebesar 0,698. Citra yang diharapkan menunjukan hubungan yang cukup kuat terhadap minat kunjungan yaitu sebesar 0,679. Dan citra pengelola memiliki hubungan yang cukup kuat terhadap minat kunjungan yaitu sebesar 0,533 .

Hasil uji koefisien determinasi menunjukan bahwa nilai $R$ square yang dimiliki koefiesien determinasi sebesar 0,670, hal ini membuktikan bahwa $67,0 \%$ minat wisatawan dapat dijelaskan variabel-variabel bebas yaitu variabel citra bayangan,citra yang berlaku, citra yang diharapkan dan citra pengelola. Sisanya $33,0 \%$ dipengaruhi oleh variabel-variabel lainnya yang tidak terdapat pada penelitian ini.

Hasil analisis regresi berganda menunjukan bahwa variabel citra yang terdiri dari, citra bayangan, citra yang berlaku, citra yang diharapkan, citra pengelola berpengaruh positif dan signifikan terhadap minat wisatawan dikarenakan nilai signifikan semua variabel $<0,05$.

Pengujian Hipotesis dilakukan dengan 2 uji yaitu uji $t$ dan uji $F$ yang mana hasil uji $t$ menunjukan bahwa variabel citra bayangan, citra yang berlaku, citra yang diharapkan dan citra pengelola memiliki nilai signifikan $<0,05$ dapat disimpulkan bahwa keempat variabel tersebut memiliki pengaruh dan signifikan terhadap minat kunjungan wisatawan. Sedangkan untuk uji $\mathrm{F}$ menunjukkan nilai signifikan 0,000. Nilai signifikan sebesar $0,000<0,05$ maka dapat disimpulkan bahwa variabel citra secara simultan berpengaruh positif dan signifikan terhadap minat kunjungan wisatawan.

Tolong ini dibuat jadi satu kalimat aj jgn dimunculkan kata kata uji lg terlalu rame. dbuatkan paragraph saja.

\section{PEMBAHASAN \\ Pengaruh Citra Desa Terunyan terhadap Minat Kunjungan Wisatawan secara Parsial}

Berdasarkan hasil ini maka pengaruh citra bayangan terhadap minat kunjungan wisatawan dapat diketahui bahwa variabel citra bayangan memiliki nilai signifikansi 0,000. Hal ini membuktikan bahwa citra bayangan berpengaruh signifikan terhadap minat kunjungan wisatawan karena nilai 
signifikan dari variabel citra bayangan lebih kecil dari 0,05 .

Pengaruh citra bayangan terhadap minat kunjungan wisatawan variabel citra bayangan memiliki 2 indikator pernyataan yang diukur dengan skala likert, indikator yang pertama adalah pengelola Kuburan Desa Terunyan ikut menjaga citra Kuburan Desa Terunyan terutama bagi wisatawan yang baru pertama kali berkunjung, dari indikator ini dipersepsikan setuju oleh wisatawan dengan nilai rata-rata 4.18 dan indikator kedua adalah pengelola mengupayakan peningkatan citra Kuburan Desa Terunyan di mata wisatawan dari indikator ini dipersepsikan setuju oleh wisatawan dengan nilai rata-rata 3.96.

Berdasarkan hasil ini maka dapat diketahui bahwa Pengaruh citra yang berlaku terhadap minat kunjungan wisatawan memiliki nilai signifikansi 0,000 hal ini membuktikan bahwa citra yang berlaku berpengaruh signifikan, karena nilai signifikan dari variabel citra yang berlaku lebih kecil dari 0,05 . Variabel citra yang berlaku memiliki 2 indikator pernyataan yang diukur menggunakan skala likert, indikator yang pertama adalah wisatawan sudah mengetahui tentang Kuburan Desa Terunyan sebelumnya, dari indikator ini dipersepsikan setuju oleh wistawan dengan nilai rata-rata 4.12. Indikator yang kedua citra Kuburan Desa Terunyan sudah baik menurut wisatawan dipersepsikan setuju oleh wisatawan dengan nilai rata-rata 4.20.

Berdasarkan hasil ini dapat diketahui bahwa pengaruh variabel citra yang diharapkan terhadap minat kunjungan wisatawan memiliki nilai signifikansi 0,005 hal ini membuktikan bahwa citra yang diharapkan berpengaruh signifikan, karena nilai signifikan dari variabel citra yang berlaku lebih kecil dari 0,05. Variabel citra yang diharapkan memiliki dua indikator pernyataan yang diukur menggunakan skala likert, indikator yang pertama adalah pengelola Kuburan Desa Terunyan mampu memberikan pelayanan yang baik bagi wisatawan, indikator ini dipersepsikan setuju oleh wisatawan dengan nilai rata-rata 3,97.Indikator yang kedua adalah wisatawan sudah merasa puas dengan pelayanan pengelola Kuburan Desa Terunyan, dipersepsikan setuju oleh wisatawan dengan nilai rata-rata 4.20.

Berdasarkan hasil ini dapat diketahui bahwa pengaruh variabel citra pengelola terhadap minat kunjungan wisatawan memiliki nilai signifikansi 0,045 hal ini membuktikan bahwa citra berpengaruh signifikan, karena nilai signifikan dari variabel citra pengelola lebih kecil dari 0,05.Variabel citra pengelola memiliki 2 indikator pernyataan yang diukur menggunakan skala likert, indikator pertama adalah pengelola Kuburan Desa Terunyan mampu memberikan pengalaman yang baik bagi wisatawan yang berkunjung, diperspsikan sangat setuju oleh wisatawan dengan nilai ratarata 4,26. Indikator yang kedua adalah rasa percaya wisatawan terhadap pengelola Kuburan Desa Terunyan tentang kenyamanan saat mengunjungi Kuburan Desa Terunyan dipersepsikan sangat setuju oleh wisatawan dengan nilai rata-rata 4.22.

\section{Pengaruh Citra Desa Terunyan terhadap Minat Kunjungan Wisatawan secara Simultan}

Pada hasil analisis regresi berganda yang telah dilakukan, 4 variabel citra telah terbukti berpengaruh signifikan terhadap variabel minat karena nilai signifikannya lebih besar dari 0,05 . Secara parsial variabel citra bayangan,citra yang berlaku, citra yang diharapkan berpengaruh signifikan terhadap minat kunjungan wisatawan karena semua variabel memiliki nilai signifikan lebih besar dari 0,05. Secara simultan variabel citra memiliki pengaruh signifikan terhadap minat kunjungan wisatawan karena memiliki nilai signifikan lebih dari 0,05 .

Hasil ini didukung oleh Gagah (2015) yang menyatakan bahwa citra suatu perusahaan memiliki pengaruh signifikan terhadap variabel minat berkunjung. Hal ini disebabkan karena citra suatu perusahaan menjadi salah satu variabel penentu tumbuhnya minat berkunjung konsumen. Selanjutnya Kadampili dan suhartanto (2000) dalam industri perhotelan menunjukkan bahwa citra dan kepuasan pelanggan berpengaruh positif terhadap minat penarik pengunjung.

\section{SIMPULAN DAN SARAN Simpulan}

Citra pengelola kuburan Desa Terunyan memiliki pengaruh positif terhadap minat kunjungan wisatawan ke Desa Terunyan. Citra tersebut terdiri dari citra bayangan (mirror 
image), citra yang berlaku (current image), citra yang diharapkan (wish image), serta citra pengelola (corporate image). Dimensi variabel citra yang mendominasi dalam mempengaruhi minat kunjungan wisatawan untuk berkunjung ke kuburan Desa Terunyan adalah citra bayangan (mirror image).

\section{Saran}

Pengelola Kuburan Desa Terunyan sebaiknya mempertahankan dan meningkatkan indikator-indikator citra yang sudah dinilai baik oleh wisatawan dan pengelola Kuburan Desa Terunyan harus tetap menjaga kenyamanan wisatawan agar wisatawan tidak takut untuk berkunjung. Hal-hal yang dapat dilakukan untuk mempertahankan antara lain mempertahankan adat dan tradisi yang sudah ada untuk tetap menarik minat wisatawan berkunjung ke Kuburan Desa Terunyan. Selain itu, pihak pengelola kuburan Desa Terunyan tetap mampu menjaga serta membuat peraturan yang lebih tegas agar tidak ada lagi pengemis ataupun pendayung yang nakal yang dapat membuat wisatawan merasa tidak nyaman untuk berkunjung.

\section{DAFTAR PUSTAKA}

Andreassen TW, Lindestad B. 1998. Customer Loyalty and Complex Service: The Impact of Corporate Image on Quality, Cutomer Satifaction and Loyalty for Customers With Varying Degrees of Service Expertises. Intenational Journal of Service Management. Vol.9 No.7.

Bimo, Gagah. 2015. Pengaruh Citra Perusahaan Terhadap Minat Berkunjung Dan Keputusan Berkunjung (Survei pada Pengunjung Taman Rekreasi PT.Selecta, Kota Batu, Jawa Timur). Jurnal Administrasi Bisnis. Vol.26 No.2.

Ghozali, Imam. 2005. Aplikasi Analisis Multivariate dengan program SPSS. Semarang: Universitas Diponegoro.

Sugiyono. 2010. Metode Penelitian Pendidikan : pendekatan Kuantatif, Kualitatif, $R \& D$. Bandung: Alfabeta.

Syarufuddin dan Suryanto. 2016. Public Relation. Yogyakarta : Andi. 